CONTRIBUTIONS FROM THE ZOÖLOGICAL LABORATORY OF THE MUSEUM OF COMPARATIVE ZOÖLOGY AT HARVARD COLLEGE. E. L. MARK, DiRECTOR.-NO. 169 .

\title{
THE MOVEMENTS OF THE SWIMMING-PLATES IN CTENOPHORES, WITH REFERENCE TO THE THEORIES OF CILIARY METACHRONISM.
}

\author{
BY \\ G. H. PARKER. \\ With 2 Figures.
}

I. INTRODUCTION.

Since the publication in 1880 of Chun's elaborate monograph on the ctenophores, it has been generally admitted, contrary to the opinion of many of the older investigators, that the swimmingplates of these animals are their principal organs of locomotion. Moreover, the ciliary nature of these organs may now be regarded as well established, and their relatively enormous size has already made them favored objects with investigators of ciliary phenomena. As is well known, these swimming-plates are arranged in rows and the members of each row, like ordinary cilia, beat metachronally, not synchronally. The explanation of this peculiarity has called forth two somewhat opposing views. According to the first of these, which has been developed chiefly by Engelmann ('68, p. 475; '79, p. 388), it is maintained that one element beats immediately after its next neighbor in a given order because of a nerve-like impulse that is supposed to pass from cell to cell and thus to bring into action in regular sequence the overlying elements. This may be called the neuroid theory of ciliary action. According to the second view, advanced in the main by Verworn ('9o, p. 175), the cause of metachronal action is not to be sought for in the cell-body proper, but rather in the mechanical effect of one cilium on another, in that the action of one cilium mechanically stimulates the next one to action. This may be called the mechanical theory of ciliary action. Because of the minute size of ordinary cilia, experimental tests of these two theories are not easily carried out; hence the anatomical conditions presented in ctenophores are of unusual importance. It is the principal object 
of this paper to discuss the cause of metachronism in ciliary action as exemplified in the swimming-plates of these animals.

The material upon which I worked consisted almost entirely of the common summer ctenophore of the New England coast, Mnemiopsis leidyi A. Agassiz, though I also made some observations on the winter species Pleurobrachia rhododactyla L. Agassiz. The work was done for the most part during the last few summers at the Wood's Hole Laboratory of the United States Bureau of Fisheries, to the officers of which I am under obligations for many kindnesses shown me.

\section{OBSERVATIONS.}

\section{Anatomical.}

Mnemiopsis leidyi is a lobate ctenophore measuring often as

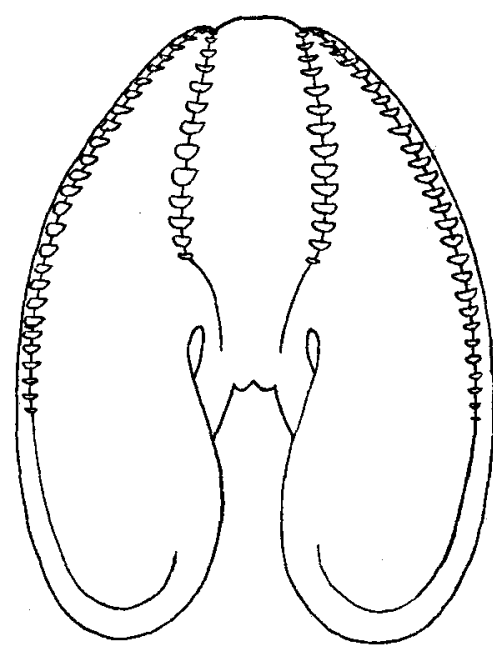

Fig. I.

Side view of Mnemiopsis leidyi. The sagittal plane corresponds to that of the paper and the aboral pole is uppermost. Two short subtransverse rows of swimming plates and two long subsagittal ones are seen converging toward the aboral pole. The subsagittal rows extend as vibratile lines far over the surface of the lobes. pairs and enter that organ as
four bands. As will be seen by comparing Figs. I and 2, the rows of swimming-plates are either long or short and the pairs

much as seven or eight centimetres in length. Its external form is shown in Fig. I, which is a view of the animal so placed that its sagittal plane corresponds to the plane of the paper. The mouth is directed downward and the two large lobes that characterize this group of ctenophores are seen at the right and left of it. The aboral pole is pointed upward and four of he eight rows of swimming-plates are shown converging toward it. Their relation to the sense body at the aboral pole can be seen clearly in Fig. 2, where it will be observed that from the most aboral plate of each row a narrow band extends to the sense body. These bands, before they reach the sense body, unite in

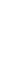


formed by the unions into the bands consist always of a long row combined with a short one. Since the long rows lie near the sagittal plane and the short ones near the transverse, they have been called, respectively, subsagittal and subtransverse. The combination of a long subsagittal row with a short subtransverse one to form a pair has long been known to be one of the structural characteristics of the lobate ctenophores, and, as will be shown later, this feature is not without its physiological significance. Each such pair, as can be seen in Fig. 2, is restricted to a quadrant of the animal's body.

The number of swimming-plates in the subsagittal and the subtransverse rows varies more or less with the size of the animals. Thus in a small specimen eight millimeters long the subsagittal rows contained each about ig plates, the subtransverse ones about I3; while in a large individual sixty millimeters long, there were about 73 plates in each subsagittal row and about 39 in the subtransverse ones. In the specimen from which Figs. I and 2 were drawn, there were about 29 plates in each subsagittal row and about 17 in each subtransverse one.

In Mnemiopsis the bands that lead from the sense body to the swimmingplates are ciliated, as in other ctenophores, and, as Samassa ('92, p. 229) has shown for other lobate forms, a band of cilia connects plate with plate.

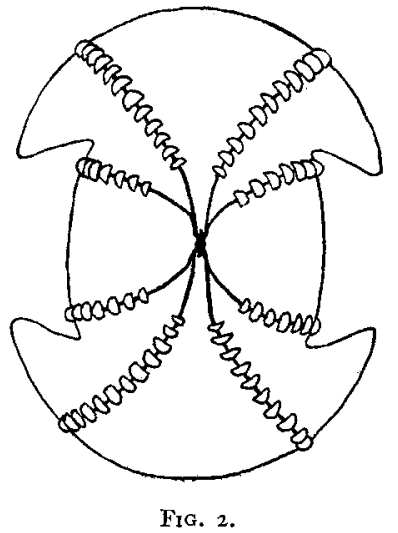

Aboral view of Mnemiopsis leidyi. The four subsagittal rows of swimmingplates, two from each lobe, and the four subtransverse ones converge on the sense body at the aboral pole. In this species, however, the spaces between the plates seem to be much more sparsely provided with cilia than in other lobate ctenophores, if, in fact, cilia are not sometimes entirely absent from these regions.

The second species upon which I worked, Pleurobrachia rhododactyla, was of simpler structure than Mnemiopsis. It belongs to the Cydippidæa and has the typical form of an oblong spheroid. Its eight rows of swimming-plates are of about equal length and can be readily distinguished as subsagittal or subtransverse only by their relations to other parts in the animal's 
body. In a specimen of average length, about sixteen millimetres, there were approximately 40 plates in each row.

\section{Physiological.}

The resting position of the swimming-plates in both Mnemiopsis and Pleurobrachia is one in which the individual plate is turned close to the body of the animal and with its tip directed orally. In action the plate makes a vigorous stroke aborally and then returns to its resting position. In consequence of such movements carried out more or less simultaneously by certain plates in each row, the animal's body is moved through the water with the mouth forward. The plates in any one row strike one after another beginning at the aboral end, $i$. e., to use the term proposed by Verworn ('go, p. I 52), they beat metachronally. Ordinarily the first plate to strike is the most aboral one and the others follow in sequence giving rise, by the order of their beat, to a wave-like appearance which progresses, of course, in an oral direction.

Chun ('80, p. I72) has shown that when in a normal animal a wave starts over one row, a like wave also starts over the other row of the same quadrant, $i$. $e$., the two rows of any quadrant act in uni on. This relation was observed by Verworn (' 9 , p. 456) in all the ctenophores that he studied, and it is certainly an invariable occurrence in Mnemiopsis, but not in Pleurobrachia. In Pleurobrachia, though the rows of plates on the same quadrant are often seen to beat in unison, they also frequently beat independently. That their beating in unison is not a mere matter of accident is seen from the fact that, whereas rows on the same quadrant often beat in unison, adjacent ones belonging to different quadrants do not beat in this manner. There can be no question, I believe, that the rule laid down by Chun, to the effect that rows on the same quadrant always beat in unison, has its exceptions, for in Pleurobrachia the two rows of any quadrant may beat independently. As might be expected from the researches of Chun ('80, p. I72), the removal of the sense body from Mnemiopsis or from Pleurobrachia is invariably followed by a complete loss of the partial or perfect unison of action between rows of plates.

Since there is an agreement in the metachronism of the two rows of plates on any quadrant in Mnemiopsis, there should 
The Movements of the Swimming-Plates in Ctenophores. 4I I

be a synchronism in the action of the corresponding plates in these two rows, and such proves to be the case. This condition is very noticeable when at the beginning of a series of swimmingplate movements, the waves run at varying rates, for when a wave passes rapidly or slowly over one row, it passes at the same rate over the other row of the same quadrant. Similar conditions were observed in Pleurobrachia when its swimming-plates were acting in unison.

The reversed action of the swimming-plates in ctenophores has been stated to occur by numerous observers, but the expression reversed action in this connection is undoubtedly somewhat ambiguous. In the so-called reversal of cilia and other like organs at least two kinds of reversal are possible: a reversal of the propagation wave, "Reizwelle" of Engelmann, and a reversal of the effective stroke of the cilia (Parker, '05, p. 9). In the first instance the question turns on the sequence in which the cilia beat; thus in the normal action of a series of cilia, element $a$ may beat first and $z$ last, the propagation wave passing from $a$ to $z$; while in reversed action $z$ would beat first and a last, the wave passing in the reverse direction. In the second instance only the effective stroke of the cilium is concerned; this may be normally toward $z$ or reversed toward $a$ irrespective of the sequence in which the cilia of the series act.

In ctenophores a reversal of the direction of the propagation wave has often been observed. This was early noticed on fragments of Beroë by Eimer ('80, p. 226), an observation confirmed on this and other species by Chun ('80, p. 182) and by Verworn ('9o, p. 167; '91, p. 459), though the latter is misquoted in this respect by Pütter ('03, p. 35). Reversal of the propagation wave occurs occasionally in Pleurobrachia. When a rapid wave from the aboral end of the animal reaches the oral limit of a row of plates, it may be reflected aborally over the row again, but it seldom retraces its course for more than one-third the whole length of the row. As Verworn ('90, p. I67; '9 I, p. 440) observed, these reversed waves can of ten be induced by stimulating mechanically the oral end of a row of swimming-plates.

In Mnemiopsis I have never observed unquestionably reversed waves, nor have I been able to induce them by special stimulation. Some slight evidence of reversal has been seen when a relatively slowly moving wave near the oral end of its course is overtaken 
by a more rapid one. This is seen to sweep over the slower wave and, as it does so, what seems to be a reversed wave starts from the point of collision and runs aborally over not more than six or eight plates at most. This short wave is the only evidence of reversal that I have found in Mnemiopsis; it is my belief that this reversal of the swimming-plate action, so common in many ctenophores, is almost entirely absent from this species.

According to previous investigators, ctenophores can reverse the effective stroke of the swimming-plates as well as change the direction of the propagation wave. Under ordinary conditions, the effective stroke carries the animal with the oral end forward; when this is reversed, the animal moves with the aboral end ahead. Chun ('80, p. I8I) mentions that this reversed form of locomotion is a regular though rare occurrence with all ctenophores, especially when by normal locomotion their oral ends collide with some fixed body. Verworn ('9I, p. 432) states that he has on rare occasions observed this reversed swimming in Eucharis and Callianira, but not in other species of ctenophores. I have never seen any evidence of the reversal of the effective stroke in either Pleurobrachia or Mnemiopsis and I am inclined to believe that Chun's statement that the effective stroke can be reversed in all ctenophores, may be a mistake based upon a confusion of this form of reversal with the reversal of the propagation wave. In Pleurobrachia it can be easily shown that when the propagation wave reverses from an oral to an aboral direction the swimming-plates continue their effective stroke in an aboral direction as before.

When a row of swimming-plates in Pleurobrachia or Mnemiopsis is cut through so as to divide it into oral and aboral portions, the plates in both parts cease to move for a short time and when they resume their activity, the two parts are found to beat differently, i. e., their propagation waves are found to be independent. In this respect the American species agrees with the European forms experimented upon by Eimer ('80, p. 227), Verworn ('90 p. I67), and others. If a row in Mnemiopsis is cut with care, the aboral part almost immediately begins to beat metachronally with reference to its fellow of the same quadrant, and the oral part reëstablishes independent movements in a few minutes or even seconds. In the quickness of recovery of the oral part Mnemiopsis is in strong contrast with Beroë and Eucharis, in which, accord- 
ing to Krukenberg ('80, p. 2) and Verworn ('9o, p. 156), the activity of the oral part may not return for an hour or so after the row is cut. The waves in the oral part of Mnemiopsis always proceed from near the cut end of the row orally; the most aboral plate to show motion, however, is not the one next the wound but usually the third or fourth from it. The oral portion will thus move its swimming-plates for hours without relation to the movements of the aboral part. I have never seen any evidence of the reëstablishment of harmony in the two parts of a severed row such as has been described by Eimer ('80, p. 229) and Verworn ('9o, p. I67; '9I, p. $\left.{ }^{6} 63\right)$. When a swimming-plate band is cut through, not where there are swimming-plates but between the most aboral plate and the sense body (compare Fig. 2), the whole row in its movements becomes independent of the sense body and if the sense body is destroyed, the coördination of the four pairs of rows entirely disappears, as has already been shown by Verworn ('9I, pp. 457-459) and others for several European species.

When a Mnemiopsis is cut in two transversely, the parts of rows on the aboral portion retain their coördination as in a normal animal; those on the oral part, as might be expected, lose all signs of such relations. It is clear from this and the preceding experiments that the coördinating influences proceed from the aboral pole, and, when this is lost, coördination disappears. In this respect my observations confirm those of Krukenberg ('8o, p. 2) on Beroë and are opposed to those of Eimer ('8o, p. 23I), who stated that the oral half of Beroë is indistinguishable in the movements of its plates from a whole animal.

When a Mnemiopsis is shaken in sea-water, it can be broken easily into fragments and the plates attached to these pieces will continue to beat rhythmically and metachronally for from one to two days. As Verworn ('9o, p. 157) has shown for Cestus, so also in Mnemiopsis, even a single plate with a small basal piece of protoplasm will beat rhythmically for a long time. This condition led Verworn to believe that each plate possessed a certain degree of autonomy, which was seen in the continued activity of the isolated plates and must be imagined to be counteracted by some influence when the plate as a member of a row was quiescent. But in my opinion the swimming-plate, when it beats, does so because it is stimulated, and its quiescence is evidence of the absence of appropriate stimuli. When it beats normally on 
a whole animal, it does so in response to a wave of stimulation from the aboral pole, the cessation of which is followed by the cessation of the movement in the plate. When one plate with a small amount of protoplasm attached continues to beat, as it often will for hours, it does so because the fragmentary condition of its base exposes this part to continual stimulation. I see no reason to assume that the plates possess an autonomy that is inhibited much of the time by the animal.

A fragment of a swimming-plate of Mnemiopsis made by splitting the plate lengthwise will continue to beat if a small basal mass of protoplasm is still attached to it. Whole swimmingplates or fragments of plates cease to beat when the base is trimmed off to such an extent that only the swimming-plate proper is left. In this respect the plates of Mnemiopsis resemble those of the ctenophores on which Verworn ('90, pp. 158, I6 I) experimented. This failure of the isolated plates to vibrate has generally been attributed to the loss of a stimulus normally received from the basal protoplasm, but Pütter ('03, p. 42) has suggested that it may be due to the rapid death of the plates after isolation from the living substance of the animal. That this is not so in Mnemiopsis is seen from the fact that a fragment of a plate cut off from its basal protoplasm and kept in sea water half an hour trembles and curves when a little picric acid is applied to it just as the living plates do on a whole animal when this reagent is poured on them. I therefore believe that the quiescence of isolated plates is due to the absence of a stimulus to contraction and not to early death.

It is evident from what has preceded that the rows of swimmingplates of ctenophores ordinarily beat in pairs corresponding to the quadrants of the animal's body and that the plates of any row beat metachronally beginning ordinarily at the aboral end. As Chun ('80, p. 172) long ago pointed out, that which regulates their beat proceeds usually from the region of the aboral pole and here four centers must be assumed, one for each quadrant of the animal's body. It is also evident that the regulating influence in its passage from the aboral pole is strictly limited to the bands leading from the sense body to the rows of plates, and to the rows of plates themselves, and that, though the waves usually start from the aboral end and progress toward the oral one, they may in some species reverse and run some distance aborally. All these 
facts are explainable on either the theory of neuroid transmission as advocated by Engelmann, or on that of mechanical transmission as put forward by Verworn; for on the former assumption the band of epithelium leading from the sense body to the oral end of a row of swimming-plates may serve as a transmitting tract, and on the latter the ciliated bands leading from the sense body to the rows of plates may serve to transmit the mechanical disturbance from the center to the plates. I propose now to turn to certain observations that are, in my opinion, inconsistent with one or other of these theories.

Since in accordance with the idea of mechanical transmission the mechanical activity of the vibratile elements is a necessary accompaniment of transmission, it follows that any means of bringing this activity to a standstill ought to check transmission. It might be supposed that the cutting off of one or more plates would produce such an effect. When this is done in Cestus, according to Verworn ('9o, p. I 73), and in Mnemiopsis, according to my own observations, the waves still pass regularly over the whole row of plates and are not interrupted by the interval from which the plates have been removed. Since, however, the spaces between the plates in Cestus, as well as in the lobate ctenophores, have been shown by Samassa ('92, p. 229) to be ciliated, it might be assumed that these cilia in their vibrations transmit the mechanical disturbance over the whole row. The assumption that in the absence of plates the cilia may transmit the disturbance is, however, in my opinion improbable, for the space made by the removal of a plate is so considerable in comparison with the length of the cilia that, unless we assume as Verworn ('9o, p. I73) does that the whole base of the plate is surrounded by cilia, I see no way by which the mechanical disturbance made by the cilia on one side of the root of the plate could influence those on the other side and thus effect transmission. As I have never seen in Mnemiopsis any reason to believe that the plates are surrounded at their bases by cilia, I do not believe that transmission can be accounted for in the present experiments by the mechanical theory, even admitting the presence of cilia between the plates.

A modification of the experiment just described has been employed by Verworn ('9o, p. I 7 I) with the view of testing further the nature of transmission. This experiment consisted in restraining a plate from beating instead of cuttin $y$ it off and then ascer- 
taining whether waves passed beyond it. When a plate in Beroë is turned aborally by a lancet point, waves from the aboral end fail to pass this plate. . If only the tip of the plate is held and the base is allowed to move, the wave passes onward to the oral portion of the row. These observations led Verworn ('9o, p. I7I) to conclude that the mechanical vibrations of the plates were necessary for transmission, and he drew this conclusion notwithstanding the fact that in Cestus he ('9o, p. I 72) found that the holding or even the pulling out of a plate did not interfere with transmission. Verworn confessed to have been astonished at the conditions found in this species, but, as already stated, he believed that they might be explained on the assumption that the base of each plate is more or less surrounded by cilia which after the removal of the plate continue to transmit mechanically. Unfortunately I have been unable to try the experiment of restraining plates in Mnemiopsis, for the rows of plates in this species, like those in Beroë, as pointed out by Krukenberg ('8o, p. Io), are so sensitive to mechanical stimulation that the moment they are touched they are drawn down into the animal's body to such an extent as to make experiments of this kind very unsatisfactory, if not impossible.

Although the great sensitiveness of the rows of plates in Mnemiopsis prevented me from trying the experiment of holding plates individually, it afforded a very natural means of checking their action. As Verworn ('go, p. I 70 ) has shown, when the middle of a row of plates is touched, the row in that region becomes depressed and the edges of the depression fold over and cover the plates. Thus in Mnemiopsis half a dozen plates may become so much restrained that they will not show the least motion and yet waves that arrive at the aboral entrance to this depression emerge from its oral end with the greatest regularity. This may happen while the covered region is under close inspection through a lens and gives not the least sign of plate or ciliary movement. I am, therefore, forced to conclude, that, contrary to the statement made by Verworn ('9o, p, I70), such restrained tracts transmit with perfect regularity even in the absence of observable ciliary and plate motion.

Kraft ('9o, p. 223) in his study of the ciliated epithelia of vertebrates, showed that, though low temperature may bring cilia to a standstill, it does not greatly check the transmitting power of the tissue. It ought, therefore, to be possible to check the action of 
plates in a ctenophore by cold and yet leave the transmitting power of the row unimpaired. To test this proposition, I passed a small curved metal tube through the substance of a Mnemiopsis directly under one of its rows of swimming-plates and at right angles to the direction of the row. The animal was anchored by being pinned in a small aquarium of sea water whose temperature was $2 \mathrm{I}^{\circ} \mathrm{C}$. Normal waves of action were seen to course over the row of swimming-plates under which the metal tube had been placed. I now passed through the tube water of a temperature between $4^{\circ}$ and $5^{\circ} \mathrm{C}$. A steady flow was kept up to insure as complete a chilling as possible of that portion of the row under which the tube went. The chilled plates soon ceased to move and the waves appeared to jump from the aboral side from which they approached the chilled region to the oral one beyond it. Sometimes half a dozen waves in rapid succession appeared thus to jump this chilled region. But the best evidence was obtained when the waves ran at considerable intervals, at which times the correspondence between the parts of the wave in front of and behind the chilled region was most striking. To be certain that there was no movement of cilia or plates in the chilled region, a small amount of powdered carmine in sea water was placed on the plates of that portion. The carmine remained motionless while wave after wave ran over the aboral and the oral parts of the row. At the close of the experiment the chilled region was allowed to regain its normal temperature, whereupon its plates became vibratile again and the waves passed without interruption. This experiment was repeated on six different individuals and with constant results. In one instance the temperature of the water used for chilling the tissue was $8.5^{\circ} \mathrm{C}$. and under this condition the cessation of movement was only partial, but in all other experiments the temperature was kept at $5^{\circ} \mathrm{C}$. or lower with the result that complete cessation of movement invariably followed. Hence it is fair to conclude that in Mnemiopsis a temperature of $5^{\circ} \mathrm{C}$. or less will check the movement of the swimming-plates without essentially altering the transmitting power of the row.

In handling ctenophores in the experiments last described, I noticed that when the row of plates under which the metal tube passed was subjected to a little local stretching by the awkward manipulation of the tube, the plates often ceased to vibrate in the stretched region. On repeating this operation I found that as a 
rule the slight stretching of a region would bring the plates of that part to a standstill, though it did not interfere seriously with transmission. But it must be noted that in such an operation much care must be used not to overstrain the tissue, for otherwise a permanent cessation of action will follow. Avoiding this difficulty, however, mechanical strain, like low temperature, may be made to check motion without interfering with transmission.

\section{THEORETIC CONSIDERATIONS.}

The results of the experiments just described, in which the swimming-plates of ctenophores were removed or restrained, or the row chilled or stretched locally, afford good grounds for denying to the mechanical theory any essential part in the explanation of ciliary metachronism. If ordinary transmission is really dependent upon the mechanical action of one element on the next, it is inconceivable how such a process can be accomplished when these elements for any reason cease to move. That transmission does take place after the swimming-plates have been brought to a standstill by physical restraint, cold, etc., is unquestionable. Verworn ('9o, p. 172) admitted surprise when he found that in Cestus transmission occurred even after the removal of a plate and he was led to assume a continuous band of cilia to account for this condition. In Mnemiopsis no such band is present and yet transmission takes place even after the removal of a plate.

The failure of a wave to pass when the plates in Beroë are restrained from moving is not, as Verworn believed, a satisfactory test of the nature of transmission, for, notwithstanding the care used in restraining the plate, the operation may influence the deeper parts of the tissue and thus check transmission as well as plate movement. The fact that transmission does occur in Mnemiopsis when the plates are restrained, shows how treacherous such negative evidence is. These facts, together with the evidence from chilled and stretched rows, show, I believe, that the mechanical theory is not a necessary part of the explanation of ciliary metachronism.

Although the mechanical theory may not be the correct explanation of transmission, its rejection does not imply a rejection of the idea that the plates are open to mechanical stimulation. Everyone who has worked with ctenophores knows how sensitive the 
plates are in this respect. The slightest touch will often cause them to vibrate and will even give rise to a wave which, beginning with the plate stimulated, runs orally over the row. This condition is undoubtedly suggestive of such a view as that advanced by Verworn; his ('9o, p. 168) ingenious experiment of attaching plate to plate by cotton filaments and thus obtaining a form of mechanical transmission shows how this idea may find application. When, however, it is remembered that in rest the plates point orally, that the propagation wave ordinarily proceeds from the aboral end of the row, and that the effective stroke of the plate is made in the aboral direction, it is clear that each plate as it goes into action does not strike toward the next plate to act but away from it and hence in a direction unfavorable for mechanical stimulation. When the propagation wave is reversed, as happens in Pleurobrachia and probably in many other ctenophores, the action of the plates is such that an oral one may well stimulate mechanically the next in turn, and, while I believe that the normal wave depends for its propagation upon a neuroid transmission, I am inclined to the opinion that the reversed waves may depend largely on mechanical transmission. As is well known, these reversed waves seldom extend far and are always insignificant as compared with the normal ones. Hence I do not believe that mechanical stimulation plays any really important part in transmitting the normal wave.

Direct stimulation seems to be a possible means of transmission over a cut in a row of plates. Since both Eimer ('8o, p. 229) and Verworn ('90, p. I67) have recorded the occurrence of this form of transmission in European species, it might be looked for in other forms, though I have been unable to find any evidence of it in Mnem. iopsis or Pleurobrachia. However, I see no reason why the vibration of a plate on the aboral side of a cut may not stimulate to action a plate on the oral side of the same cut provided the two plates are brought close enough together. The subject is worthy of further investigation.

Most of the observations that have been brought forward against the mechanical theory might now be urged in favor of the neuroid theory, for transmission without ciliary or plate motion is what is implied by this view. The idea that the movement of the swimming-plates is controlled by nerves was held by some of the older investigators such as Eimer ('73, p. 45) and Krukenberg 
('80, p. 5), though on insufficient grounds, for no one has ever demonstrated that nerves are connected with these plates. Engelmann (" 87, p. 442) has used the expression "innervated" in reference to the rows of swimming-plates, but it is perfectly evident from other statements in his account (p. 440) that this term is used in a physiological sense and not in an anatomical one, and that he consistently adheres to his original idea ('79, p. 395) of epithelial transmission. Chun ('8o, p. I73) made perhaps the best brief statement of the mechanism of transmission in ctenophores when he declared that the rows of epithelial cells served as nerves. It is in my opinion an open question whether in any instance cilia are really controlled by nerves. Such a control is denied by Verworn ('95, p. 25I), though Pütter ('o3, p. 98) in his recent survey of the whole subject of ciliary activity states that in the larvæ of certain annelids such control occurs. It seems to me that Pütter's grounds are insufficient for such a conclusion; but, however this question may stand for annelids, in the ctenophores not the least histological evidence has ever been advanced to show that their rows of plates are accompanied by nerves. Samassa ('92, p. 226), who has studied this matter with care, denies that ctenophores have any nervous system properly so called and points (p. 230) to the epithelial bands in Beroë as the transmitting organs. There thus seems to be good reason for believing that the epithelial cells on the rows of swimming-plates in ctenophores transmit impulses that control the metachronism of these plates; in other words the neuroid theory, contrary to the statement made by Verworn ('90, p. 175), is tenable. Such a conclusion is entirely consistent with the results of Gruetzner ('82) and of Kraft ('9o) in their experiments on transmission in the ciliated epithelia of the higher animals, for both investigators found it necessary to assume a deep-seated cellular transmission to explain the spread of ciliary disturbances in active and in quiescent fields of cilia.

Although the results of my experiments make me confident that the metachronism of the swimming-plates of ctenophores is due to neuroid transmission, I do not believe that the facts warrant the extreme position taken by Engelmann ('87, p. 440) that no form of mechanical transmission obtains. It seems to me much more likely that, as Chun ('8o, p. I74) has declared, mechanical action is a subordinate though real factor in transmission. In my 
opinion, this factor would never of itself result in giving rise even to a single full wave, though it might, if vigorously started, carry a wave over a small number of plates. Its influence at most would be only of a subordinate character. Chun's view that both neuroid and mechanical factors take part in transmission has been adopted by Pütter ('03, p. 98).

While mechanical transmission may be of only subordinate importance, mechanical stimulation must be regarded as of no small significance. It has already been pointed out that a plate, if mechanically stimulated, may become the point of origin of a wave which will be transmitted over the row of plates in all respects normally. Hence mechanical stimulation will not only bring a plate into action but will induce the formation of a normal neuroid propagation wave.

If the ciliated epithelia of the higher animals and such specialized structures as the swimming-plates of the ctenophores are controlled by impulses that are passed in a definite direction and within circumscribed limits from cell to cell, it seems highly probable that many of the coördinated responses of the lower metazoans and of the early larval stages of the higher forms may depend upon this form of mechanism rather than on any kind of true nervous organization. Thus it may well be that the slow but uniform responses of sponges to local stimulation may be due to neuroid transmission through their epithelial layers and not through true nervous tissue, which, as is well known, has been sought for in vain in these animals. The exact orientation to light of larval sea urchins at the blastula or gastrula stage involves a certain coördinated beat of the cilia which, in the absence of nervous elements, may well be due to neuroid transmission. Thus animals in such early stagess of growth may carry out by means of their epithelia reactions which in later stages would be performed by a true nervous mechanism. Conditions of this kind lead me to believe that before primitive metazoans possessed any nervous organs whatever, they probably had in their epithelia organs which exhibited the most fundamental property of nervous tissue, namely, a capacity to transmit in a prescribed direction impulses to motion. From epithelia of this kind sense organs and central nervous organs were probably evolved, and yet this evolution did not bring about the entire suppression of these primitive prenervous mechanisms; for the ciliated epitheila of the highest 
animals, as well as the swimming-plates of the ctenophores, still possess the power of neuroid transmission.

\section{SUMMARY.}

I. In Mnemiopsis and Pleurobrachia the swimming-plates normally beat metachronally beginning at the aboral ends of the rows.

2. In Mnemiopsis the two rows of plates belonging to the same quadrant of the animal's body beat in unison. In Pleurobrachia this is also often true, but all eight rows in this ctenophore may beat independently.

3. The propagation wave ("Reizwelle" of Engelmann) shows scarcely any evidence of reversal in Mnemiopsis, but often reverses in Pleurobrachia.

4. Reversal of the effective stroke of the plates was never observed in Mnemiopsis or in Pleurobrachia.

5. On cutting a row of plates in Mnemiopsis transversely, the oral part quickly recovers and begins beating, but not in unison with any other part; the aboral part also recovers soon and beats in unison with the other row of its quadrant.

6. A single isolated plate will beat if it retains a small amount of basal protoplasm.

7. Plates without basal protoplasm will not beat, though they are not dead.

8. Loss of a plate in a row does not prevent the passage of a wave even in Mnemiopsis where the cilia on the rows do not always form continuous bands.

9. When the plates on part of a row in Mnemiopsis are restrained from moving, an impulse to plate movement may still be transmitted.

Io. Cooling a part of a row with water at $5^{\circ} \mathrm{C}$. will bring the movement of the plates to a standstill, but not interrupt transmission.

I . Stretching part of a row will cause local cessation of movement, but will not interrupt transmission.

12. The metachronism of the plates in ctenophores cannot be explained as a result of the mechanical influence of one plate on its neighbor, but the facts observed necessitate the assumption of a deep-seated transmission from cell to cell, nerve-like in character. 
The Movements of the Swimming-Plates in Ctenophores. 423

13. This neuroid transmission is probably supplemented by mechanical transmission, which of itself is insufficient to carry forward a normal wave.

I4. Phylogenetically an epithelium with neuroid transmission probably preceded true nervous structures and such an epithelium is in all likelihood the only means of transmission in many animals at their earliest larval stages (blastulæ, gastrulæ, etc.) and in such primitive forms as sponges.

\section{BIBLIOGRAPHY.}

Chun, C., '80.-Die Ctenophoren des Golfes von Neapel. Fauna und Flora des Golfes von Neapel. I. Monographie. xviii, 3I3 pp., i 8 Taf:

Eimer, T., '73.-Ueber Beroë ovatus. Zoologische Studien auf Capri. I. 92 pp., 9 Taf.

'8o.-Versuche über künstliche Theilbarkeit von Beroë ovatus. Arch. f. mikr. Anat., Bd. I7, pp. 213-240.

Engelmann, T. W., '68.-Ueber die Flimmerbewegung. Jena Zeitschr., Bd. 4, pp. $32 \mathrm{I}-478$.

'79.--Physiologie der Protoplasma- und Flimmerbewegung. Hermann, L., Handbuch der Physiologie, Bd. I, Theil r, pp. 343-408.

'87--Ueber die Function der Otolithen. Zool. Anz., Jahrg. 10, No. 258, pp. 439-444.

Gruetzner, P., '82.-Zur Physiologie des Flimmerepithels. Physiol. Studien, pp. I-32.

KRAFT, H., '9o.-Zur Physiologie des Flimmerepithels bei Wirbelthieren. Arch. f. ges. Physiol., Bd. 47, Hefte 4, 5, pp. 196-235.

Krukenberg, C. F. W., '80.-Der Schlag der Schwingplaettchen bei Beroë ovatus. Vergleichend-physiologische Studien zu Tunis, Mentone und Palermo, Abt. 3, pp. I-23.

Parker, G. H., '05.-The Reversal of Ciliary Movements in Metazoans. Amer. Jour. Physiol., vol. I2, No. I, Pp. I-I6.

PÜtrter, A., 'o3.-Die Flimmerbewegung. Ergeb. Physiol., Jahrg. 2, Abt. 2, pp. I-IO2.

Samassa, P., '92.-Zur Histologie der Ctenophoren. Arch. f. mikr. Anat., Bd. 40, pp. 157-243, Taf. 8-12.

Verworn, M., 'go.--Studien zur Physiologie der Flimmerbewegung. Arch. f. ges. Physiol., Bd. 48, Hefte 3, 4, pp. 149-I80.

'9r.-Gleichgewicht und Otolithenorgan. Arch. f. ges. Physiol., Bd. 50, Hefte 9, 10, pp. 423-472.

'95.-Allgemeine Physiologie. Jena, 8vo, xii,$+ 5^{84} \mathrm{pp}$. 